\title{
O interculturalismo político e a integração dos imigrantes: o caso português
}

Paulo Manuel Costa'

\section{Resumo}

A política de integração dos imigrantes tem por finalidade promover a coesão social e gerar um sentimento de identificação com a comunidade nacional por meio do estabelecimento de laços de união e da partilha de valores e práticas entre todos os residentes em um território. Em Portugal, nos últimos anos, a interculturalidade tem sido apresentada como um dos princípios estruturantes da política de integração dos imigrantes. Neste artigo, pretendemos mostrar como essa intenção política encontrou tradução nos dois primeiros Planos para a Integração dos imigrantes, procedendo à seleção e à apreciação das medidas mais diretamente direcionadas para a promoção da interculturalidade. Concluímos que a grande maioria das medidas apresentadas como interculturais nos dois documentos tem como objetivos mostrar a diversidade cultural existente $e$ capacitar a administração pública para lidar com a diversidade. Se essas medidas são importantes para promover e facilitar a integração dos imigrantes, elas não parecem suficientes para revelar uma abordagem interculturalista da política de integração portuguesa.

Palavras-chave: Imigração. Integração. Interculturalismo. Diversidade. Portugal.

\section{Introdução}

A política de integração dos imigrantes tem por finalidade promover a coesão social, criando condiçôes para que eles possam beneficiar-se de condiçôes sociais, econômicas e culturais semelhantes ou aproximadas às dos nacionais, ao mesmo tempo em que procura gerar um sentimento de identificação com a comunidade nacional por meio do estabelecimento de laços de união e da partilha de valores e práticas entre todos os residentes de um determinado território.

I Doutor em Ciência Política. Professor Auxiliar no Departamento de Ciências Sociais e de Gestão da Universidade Aberta - Portugal. Investigador no Centro de Estudos das Migrações e das Relações Interculturais (CEMRI).E-mail:pmcosta@uab.pt 
O sucesso desse processo de integração está dependente da atuação de três atores fundamentais: o Estado, os grupos e os indivíduos. E é condicionado por uma diversidade de fatores, como: a política de gestão dos fluxos migratórios, o pluralismo existente, a proximidade cultural ou o tipo de ligação com o grupo de origem e o Estado.

Considerando a composição em concreto das medidas adotadas, nomeadamente, os seus objetivos e os resultados a alcançar, é possível abordar, no essencial, dois modelos de integração: o assimilacionista e o multiculturalista.

Em termos muito sintéticos, o assimilacionismo procura promover a aquisição pelo imigrante das práticas e dos valores que caracterizam a comunidade na qual ingressa, com as quais poderá ter uma maior ou menor identificação, mas que lhe permitirão o estabelecimento das relaçôes sociais necessárias para a obtenção de um trabalho e da subsequente ascensão social.

Por sua vez, o multiculturalismo defende que, no processo de integraçáo, ninguém pode ser obrigado a renunciar à sua cultura de origem, pois esta serve de referencial para que cada um perceba o seu lugar no mundo e escolha o modo como pretende viver a sua vida. Por isso, seria necessário o reconhecimento dos grupos minoritários e a preservação dos seus princípios e práticas na esfera pública. Na prática, isso significaria a atribuição ao grupo do poder de mediar a incorporação dos indivíduos na comunidade alargada.

A ideia de valorização e de defesa da diferença pelo multiculturalismo é bastante atrativa e possibilita evidenciar situaçóes em que a diferença se pode transformar em discriminação e/ou colocar em desvantagem os membros de alguns grupos minoritários. No entanto, a conceptualização política do multiculturalismo, enquanto alternativa de integração, apresenta, ainda, algumas limitaçóes e náo tem sido capaz de responder satisfatoriamente, por exemplo, aos problemas da coesão social e à eventual essencialização das culturas maioritária e minoritárias.

Se, em si mesmo, o reconhecimento dos grupos não é necessariamente negativo, a defesa intransigente e a sobrevalorizaçáo das culturas e das práticas dos grupos e o papel que lhes é atribuído podem acabar por condicionar e favorecer a essencializaçáo das culturas minoritárias, uma vez que a preservaçáo e o controle do grupo sấo condiçóes necessárias para a sua afirmação no espaço público e para a manutenção do poder no interior do grupo. Esta "cristalização" 
das culturas e dos grupos facilita a fragmentação da comunidade alargada em grupos separados por linhas culturais, étnicas ou raciais, sem que sejam estabelecidas relaçóes significativas entre eles, pois estas não são necessárias e podem mesmo ser "perigosas" se questionarem ou introduzirem alguma incerteza ou dúvida no seio do grupo.

A divisão da comunidade em grupos é uma dificuldade para o multiculturalismo porque as pessoas não estão apenas em um território, nem o Estado é algo que esteja ao serviço dos grupos. Efetivamente, o conceito de Estado é constituído por três elementos fundamentais: o povo, o território e o poder político soberano. O povo é a base do Estado e a razão para a sua existência, pois é, em seu nome e para seu benefício, que é exercido o poder soberano, servindo o território para a delimitação da área sobre o qual esse poder pode ser exercido. Por isso, o povo reveste sempre certa exclusividade, de modo a distingui-lo dos outros povos; todavia, esse caráter distintivo parece que somente pode ser alcançado se existir algo que ligue os seus membros, que os particularize, ou seja, parece necessário que estes partilhem objetivos, princípios e valores que justifiquem a vivência em conjunto, em um mesmo território, de pessoas diferentes e que sustentem e fundamentem a cooperação e a reciprocidade necessárias para a vida em sociedade.

A sugestão de um modelo intercultural de integraçáo permite obviar a esta dificuldade do multiculturalismo, na medida em que ele não considera suficiente o reconhecimento das culturas dos grupos minoritários e defende a necessidade de promover a interaçáo entre eles. Por isso, o interculturalismo parece ter um grande potencial enquanto estratégia de integraçáo. No entanto, é preciso ter presente que ele surgiu associado à questão da linguagem e da comunicação; logo, a sua extensão a outras áreas, como a política, ainda carece de alguma conceptualização.

Além disso, a via intercultural parece ser bastante mais exigente do qualquer um dos "tradicionais" modelos de integração, não só porque exige uma reformulação dos instrumentos e das medidas tradicionais da ação política mas também porque supóe um maior envolvimento de todos os participantes (Estado, grupos, indivíduos) como condição para o seu sucesso. 


\section{0 modelo intercultural de integração}

As mudanças que são impostas pelo interculturalismo e que o separam do multiculturalismo podem ser exemplificadas com as sugestôes de Alexander (2007) para as políticas locais relativas aos imigrantes e às minorias. Assim, o autor defende que o modelo intercultural deve enfatizar a comunicação intercultural, em detrimento de projetos multiculturais que celebrem a diversidade, e que a política intercultural, embora seja sensível às necessidades das minorias, deverá minimizar as medidas "étnicas"; por outro lado, as associaçôes de imigrantes devem ser apoiadas como agentes de integração na sociedade, em lugar de se procurar fomentar a sua capacitaçáo e de lhes ser delegada a prestação de serviços; também deve ser feito um uso intercultural simbólico do espaço, em vez de utilizá-lo preferencialmente para mostrar expressóes físicas do outro (ALEXANDER, 2007, p. 211-213), ou seja, propóe um afastamento em relação ao multiculturalismo, na medida em que este, ao acentuar a diferença cultural, pode acabar por contribuir ou manter a segregação das minorias étnicas, mas também se distingue do assimilacionismo, porque não desvaloriza o papel dos grupos étnicos no processo de integração (ALEXANDER, 2007, p. 210).

$\mathrm{Na}$ mesma linha de propostas, Wood e Landry (2008) defendem que os processos de consulta e participaçáo estáo frequentemente desligados da complexidade das relaçóes interculturais, pois, nomeadamente, não têm "em conta" a existência de múltiplas pertenças e ligaçôes (WOOD; LANDRY, 2008, p. 252). Para além disso, é necessário que esses processos decorram em espaços e locais interculturais, como as escolas ou os centros de saúde, ou seja, em que não exista homogeneidade étnica dos participantes. Ao mesmo tempo, os assuntos em discussão não devem estar limitados aos interesses e às necessidades específicas dos membros dos grupos minoritários, mas devem ter um âmbito mais alargado (WOOD; LANDRY, 2008, p. 252), ou seja, o que se pretende náo é que as pessoas participem na resolução de questóes "étnicas", mas que a sua participação se estenda a todos os assuntos da comunidade.

Os processos de comunicação e interação interculturais não são fáceis, uma vez que existem várias barreiras ao sucesso dos encontros interculturais. Segundo Wood e Landry (2008, p. 50), as teorias da "distância cultural" (culture-distance hypothesis) e da "atração-similitude" (similarity-attraction hypothesis) ajudam-nos a perceber isso, uma vez que elas estabelecem que, 
quanto maior for a distância entre as culturas, maiores serão as dificuldades para atravessar as fronteiras culturais entre elas e que, em geral, as pessoas preferem estar com aqueles com quem partilham as mesmas características.

Ao mesmo tempo, os vários grupos parecem fazer avaliaçôes diferentes sobre a importância e o contributo de cada indivíduo para a diversidade cultural. Isso mesmo, tivemos a oportunidade de verificar, em trabalho de investigação anterior, sobre Portugal, no qual se pretendeu examinar as dinâmicas de integração política das comunidades brasileira e cabo-verdiana residentes na Área Metropolitana de Lisboa ${ }^{2}$.

Neste trabalho, os dados da pesquisa empírica foram obtidos mediante a aplicação de um questionário a uma amostra não representativa de 200 brasileiros, 200 cabo-verdianos e 200 portugueses (como grupo de controle) residentes na área metropolitana de Lisboa, que tivessem entrado em Portugal há pelo menos seis meses e tivessem idade superior a 18 anos. O questionário foi constituído por 114 questôes de resposta fechada que incidiam sobre os seguintes temas: a titularidade da nacionalidade portuguesa; a relação com pessoas de outros grupos étnicos ou religiosos; a percepção do papel dos imigrantes; o grau de identificação com a comunidade portuguesa; a participação na vida pública; e, a aceitação da diversidade cultural. Como a determinação da amostra da pesquisa não foi estatística, a análise dos dados reveste um caráter exploratório, refletindo a percepção subjetiva de um grupo de imigrantes e de portugueses sobre a integração dos imigrantes e a sua participação na vida social e política portuguesa.

Uma das questôes colocadas no questionário incidia sobre a opinião que os inquiridos tinham sobre o contributo dos imigrantes e das minorias étnicas para a diversidade cultural da sociedade portuguesa. Para isso, foram-lhes apresentadas cinco hipóteses possíveis de resposta (Tabela 1).

2 Projeto de investigação "Cidades Multiculturais e Integração Política dos Imigrantes na Área Metropolitana de Lisboa”, apoiado pelo ACIDI/Observatório da Imigração, tendo o trabalho de campo decorrido nos anos de 2008 e 2009 
Tabela I - Contributo dos imigrantes e das minorias para a diversidade cultural em Portugal

\begin{tabular}{lccc}
\hline & Brasileiros & Cabo-verdianos & Portugueses \\
\hline $\begin{array}{l}\text { Enriquecem a diversidade cultural do } \\
\text { país }\end{array}$ & $25,5 \%$ & $65,5 \%$ & $22,5 \%$ \\
\hline $\begin{array}{l}\text { Contributo insuficiente por falta de } \\
\text { oportunidades }\end{array}$ & $3,5 \%$ & $8,0 \%$ & $19,5 \%$ \\
\hline $\begin{array}{l}\text { Não dão contributo específico, } \\
\text { adaptando-se }\end{array}$ & $1,0 \%$ & $1,0 \%$ & $16,0 \%$ \\
\hline A diversidade é prejudicial & $0,5 \%$ & - & $13,0 \%$ \\
\hline Outras situações & $69,0 \%$ & $25,0 \%$ & $25,0 \%$ \\
\hline Não sabe/não responde & $0,5 \%$ & $0,5 \%$ & $4,0 \%$ \\
\hline & Fonte: Costa (20/2, p. 253). & & \\
\hline
\end{tabular}

Os dados apurados mostraram que os cabo-verdianos faziam uma apreciação mais positiva do contributo dos imigrantes e das minorias étnicas para a diversidade cultural. Por sua vez, os portugueses avaliavam esse contributo de uma forma mais desfavorável, fosse pela insuficiência ou inexistência de contributo, fosse pela atribuição de um valor negativo à diversidade cultural.

Quanto aos cidadãos brasileiros, eles escolheram preferencialmente a resposta "outras situaçóes". Sempre que os entrevistados respondiam "outras situações", era-lhes pedido que concretizassem o tipo de contributo que entendiam que era dado pelos imigrantes e pelas minorias. Neste caso, a maioria das respostas sugeriu o respectivo contributo para a economia e o emprego.

A taxa especialmente elevada desta resposta entre os brasileiros, em comparaçáo com os outros dois grupos, poderá ser explicada pelo fato da sua entrada no país ter sido mais recente, uma vez que cerca de 56\% dos brasileiros entrevistados tinham entrado em Portugal nos cinco anos anteriores. Provavelmente os brasileiros, estariam, ainda, muito influenciados pelas razóes que justificaram a sua emigração e permanência em Portugal, e ainda não teriam tido possibilidade de estabelecer e valorizar outro tipo de ligação com o país de acolhimento para além daquelas que estavam associadas ao seu projeto migratório pessoal. 
Como tal, parece que a definição de uma política intercultural precisa considerar o modo como os vários grupos avaliam o seu papel e o seu contributo para a comunidade, a diferente apreciação qualitativa que fazem sobre os assuntos em debate ou o grau de facilidade que cada grupo poderá ter no acesso ao espaço público e que poderá determinar o seu nível de participação.

De acordo com Wood e Landry (2008, p. 215), o interculturalismo não é algo que possa ser "imposto a partir de cima”. É necessário criar as condições para que as pessoas sintam necessidade de conhecerem umas às outras e de partilharem um propósito comum. Deste modo, o interculturalismo não é um instrumento que utiliza a diversidade cultural como uma via para valorizar a cultura maioritária, mas antes usa a diversidade como um ponto de partida para a construçáo de algo novo que se constitua como um propósito comum a todos os residentes no território.

Para isso, o interculturalismo terá de se afastar daquilo que Walsh (2003, p. 43) designa por "tratamento antropológico da tradição folclórica", na qual se procede a uma política de representação das minorias que acaba por servir para fixar e reforçar estereótipos. Segundo a autora, isso sucederá, por exemplo, quando a assunção da interculturalidade na política e no discurso do Estado visa apenas incorporar as reivindicaçôes e os discursos alternativos no aparelho estadual, sem que haja intenção de transformar o poder, o saber e o ser (WALSH, 2003).

Para Garcês (2009, p. 27), o interculturalismo não pode ser um simples reconhecimento ou tolerância da alteridade, uma vez que ele utiliza um conjunto de práticas de construção e de enriquecimento que supóem o conflito e a resistência para conseguir novos espaços de poder; ou seja, o interculturalismo político não é um instrumento para gerir o outro e a diversidade, nem é um ideal de convivência pacífica e harmônica, mas um campo de luta e de conflito (GARCÊS, 2009, p. 40), em que todos participam e defendem os seus pontos de vista, e isso, em última análise, pode questionar as práticas e os discursos oficiais.

Sendo assim, e como sugerem Wood e Landry (2008, p. 293), uma política interculturalista não pode ser edificada apenas a partir de dados "estáticos" sobre a diversidade existente em determinado local, sendo necessário analisar os seguintes: "com que frequência ou facilidade as diferentes etnias se 
misturam?" ou "em que medida as pessoas com diferentes etnias ou culturas efetivamente cooperam e colaboram?”.

Deste modo, se o reconhecimento da diversidade é uma condição para o desenvolvimento de uma política interculturalista, a sua existência e o seu reconhecimento não sâo suficientes para demonstrar a adoção política do interculturalismo.

A avaliaçáo do grau de receptividade à diversidade e ao interculturalismo pode ser feita por meio da utilização de múltiplos indicadores de medição. Wood e Landry (2008) sugerem, então, alguns desses indicadores possíveis:

a) Em matéria de diversidade, os indicadores propostos incidem sobre quatro áreas: a estrutura institucional, o ambiente de negócios, a sociedade civil e o espaço público (p. 299).

i) $\mathrm{Na}$ estrutura institucional, podem utilizar-se indicadores como o acesso à nacionalidade, a existência de legislação antidiscriminação, a formação para a diversidade cultural nas instituiçôes públicas ou o nível de diversidade cultural existente nos órgãos de governo eleitos comparativamente com os dados demográficos (p. 299-300).

ii) $\mathrm{Na}$ área do ambiente de negócios, são sugeridos indicadores como as práticas de recrutamento ou a composição étnica dos órgãos de direção das empresas (p. 300-301).

iii) Quanto à sociedade civil, pode recorrer-se a indicadores que meçam a diversidade da representação nos órgãos de gestão dos serviços de saúde, segurança social ou educação, a composição das organizaçóes da sociedade civil ou a participaçáo e a imagem das minorias nos meios de comunicação social (p. 301-302).

iv) Por fim, em relação ao espaço público, pode atender-se ao grau de mistura nos bairros habitacionais, ao nível de utilização de equipamentos públicos (como bibliotecas, piscinas ou centros comunitários) ou à programação cultural (p. 303).

- Por sua vez, os indicadores relativos ao interculturalismo deveráo apreender as várias formas sociais e culturais que podem mostrar a mistura, como poderão ser os casamentos inter-raciais, os produtos culturais de fusão ou a presença de diversidade cultural nos edifícios 
O interculturalismo político e a integração dos imigrantes: o caso português | Paulo Manuel Costa

ou na arte pública (p. 304).Logo, não é suficiente a afirmação política e a valorização discursiva da interculturalidade enquanto estratégia de ação, pois o seu sucesso está dependente de uma mudança profunda no modo de organizaçáo política e o seu impacto é transversal a toda a sociedade.Dado o exposto, a definição e a execução de uma política intercultural de integração supóem que se reúnam várias condiçôes:o despertar do poder político para a problemática da diversidade cultural, traduzindo-se isso na implementação de uma política que não só reconhece e tolera a diferença mas a utiliza para gerar um sentimento de uniáo entre todos os cidadáos e um sentimento de pertença que supere as fronteiras do grupo cultural, religioso ou étnico;a sensibilização dos atores públicos e privados para a diversidade cultural e para a aquisição de competências interculturais, visando a criar a abertura para a aceitação e a compreensão do outro e a disponibilidade para a procura de soluçóes inclusivas;a promoção da interação dos cidadáos e dos grupos no espaço público e o seu envolvimento no estabelecimento de novos laços e na construção de novas soluçôes coletivas;a criação de espaços e de momentos para a interação, a participação na tomada de decisões e a resolução de conflitos, pois a interação e a participação são fundamentais e o interculturalismo promoverá mudanças com impacto político, as quais inevitavelmente seráo geradoras de tensóes e de conflitos, os quais não podem ser ignorados, nem se podem generalizar de um modo incontrolável, pelo que precisam de ser geridos e canalizados para garantir a expressão do seu potencial criador.

Como se percebe, estamos perante condiçóes muito exigentes, uma vez que elas não só obrigam a um reposicionamento individual, a uma mudança na intervenção e na participação dos cidadãos e dos grupos e a uma reformulação institucional mas também implicam uma revisão do modo como nos vemos, como vemos os outros e como nos relacionamos.

Apesar disso, e do caráter ainda exploratório e algo vago do interculturalismo político, ele começa a ter uma expressão crescente no espaço público. Embora a teorização sobre o interculturalismo político seja praticamente inexistente em Portugal, ele começa a ser apontado como uma via possível ou desejável para a integração dos imigrantes, para o que terá contribuído o destaque que lhe foi dado pelos Planos para a Integração dos Imigrantes (PII). 


\section{A política de integração dos imigrantes em Portugal}

Os planos para a integração dos imigrantes foram aprovados em $2007^{3}$ e em $2010^{4}$, e sistematizam um conjunto de medidas que visam a promover a integração dos imigrantes residentes em Portugal. As medidas previstas incidem sobre várias áreas setoriais (educação, saúde, justiça, emprego etc.), demonstrando o caráter transversal da política de integração social.

Em termos de enquadramento teórico, os PII não são acompanhados pela descriçẫo da situação dos imigrantes que justifica a necessidade de intervenção pública e só apresentam uma breve síntese dos objetivos a atingir, o que, em termos gerais, nos parece insuficiente para fundamentar uma política pública.

Em qualquer caso, no primeiro plano (PII1), a interculturalidade é indicada como um dos princípios orientadores do processo de integração dos imigrantes, sendo um entre 13 princípios destacados. A interculturalidade é-nos apresentada como uma via para garantir a "[...] coesão social, aceitando a especificidade cultural e social de diferentes comunidades e sublinhando o caráter interativo e relacional entre as mesmas, suportado no respeito mútuo e no cumprimento das leis do país de acolhimento" (DIÁRIO DA REPÚBLICA, 2007, p. 2964-3).

O fato da interculturalidade nos aparecer em uma longa lista de princípios orientadores e ser o quarto na ordem da sua apresentação parece logo sugerir que não se pretende afirmar ou demonstrar a adoção de um modelo ou de uma via intercultural de integração. $\mathrm{Na}$ realidade, isso representaria uma mudança de tal forma significativa nas políticas públicas relativas à imigração e à relação entre grupos que justificaria que a interculturalidade aparecesse como agregadora ou estruturante de todo o plano de ação e não apenas como mais um princípio.

$\mathrm{Na}$ caracterização do princípio de interculturalidade é estranha a referência ao "cumprimento das leis", não porque exista necessariamente uma incompatibilidade genérica entre a lei e a interculturalidade, mas porque se é a lei que delimita o modo como a interatividade e o relacionamento entre as "comunidades" deverá decorrer, parece que, em abstrato, a imposição

3 Resolução do Conselho de Ministros nº 63-A/2007 (DIÁRIO DA REPÚBLICA, 2007)

4 Resolução do Conselho de Ministros no 74/20I0 (DIÁRIO DA REPÚBLICA, 2010). 
unilateral dessas condiçóes e dos resultados que podem ser aceites esvazia a potencialidade da interculturalidade enquanto via para alcançar um novo quadro de relacionamento entre os grupos e as culturas. Efetivamente, em regra, a menos que a lei resulte ela própria de uma interação intercultural, refletirá, sobretudo, o ponto de vista maioritário, pelo que se se pretende promover a interculturalidade parece que tem de se aceitar que a lei possa ser questionada, de modo a integrar ou a refletir a diversidade existente.

O segundo plano para a integração (PII2) procedeu a uma reformulação das áreas de intervenção passando a prever uma nova área denominada de "promoção da diversidade e interculturalidade", enquanto no plano anterior a interculturalidade estava organizada como "eixo transversal". Esta alteração não é justificada, pelo que não fica clara a razão da mudança. Em qualquer caso, essa opção parece preferível, uma vez que nos dois planos não se descortina a adoção de uma política interculturalista, mas mais a adoção de medidasque, em alguns casos, são aceitas como interculturais.

As medidas interculturais previstas nos dois PII incidem, principalmente, sobre as áreas em que o interculturalismo tem desenvolvido uma maior conceptualização, como a cultura, a língua e a educação, mas abrangem, também, outras áreas como os media, o desporto ou a administração pública.

Essas medidas podem ser agrupadas em quatro grandes tipos:

- a promoção da formação dos funcionários públicos para a interculturalidade (professores, profissionais de saúde, profissionais que prestam atendimento em serviços públicos);

- a colocaçáo de mediadores socioculturais (em escolas e unidades de saúde);

- a sensibilização para a diversidade existente e o incentivo ao desenvolvimento de iniciativas públicas para a sua divulgação (em especial através dos media e da cultura);

- a investigação, a produção e a divulgação de materiais interculturais de formação.

Naturalmente, a expressão da diversidade cultural e a capacitação dos funcionários públicos para lidarem com a diversidade e as especificidades culturais dos imigrantes são importantes para promover e facilitar a sua integração, 
mas elas não parecem suficientes para revelar uma abordagem intercultural de integração, pois esta terá de pretender ir mais além da mera aceitação da diversidade e visar à construçáo de uma cultura comum inclusiva em que todos possam participar e na qual todos se revejam.

No entanto, quando analisamos esses planos para a integração, temos dificuldade em descortinar medidas que efetivamente promovam a interação e o diálogo entre as culturas ou que criem novos espaços para o envolvimento e a participação dos cidadãos.

Assim, por exemplo, embora o PII1 previsse a criação de conselhos consultivos municipais para a participação das associações de imigrantes nas políticas de acolhimento e integração (medida 95), estes não apresentam um caráter intercultural, uma vez que privilegiam uma participaçáo étnica na abordagem de temas específicos ligados aos imigrantes.

Por outro lado, embora os planos prevejam várias medidas de apoio ao associativismo imigrante, as quais, em termos gerais, se poderiam classificar de medidas de capacitação das associaçóes para a intervenção pública (por exemplo, disponibilização de recursos - medida 98; formação de quadros medida 99; apoio na gestão de projetos - medida 97), a ação estatal nesse domínio, para além de parecer excessiva e correr o risco de gerar dependência e de condicionar a dinâmica associativa, acaba por orientar a intervenção das associaçôes de imigrantes para o processo social de integração, reduzindo ou limitado, de fato, a sua intervenção política.

Para além disso, a participação institucional das associações nos processos de decisão política está, em grande medida, limitada à participação em órgãos consultivos com limitada ou nenhuma capacidade de decisão, com a agravante dos representantes nesses órgáos serem escolhidos com base na sua origem étnica, sobrelevando o caráter étnico da representação, como sucede com o Conselho para as Migraçóes, a funcionar junto do Alto Comissariado para as Migraçôes.

Naturalmente, não se ignora a importância de assegurar a participação das associaçóes de imigrantes na discussão e na aprovação de medidas relativas à imigração, mas o Conselho para as Migraçóes não revela um caráter intercultural, não só porque os assuntos abordados são muito específicos e próprios mas também porque o elevado número de representantes ministeriais 
cria um desequilíbrio de poder no órgão, assim como as relações entre grupos estão, em larga medida, restringidas às minorias, perdendo-se o seu potencial integrador.

Quanto aos órgãos de decisão política, existe a percepção pública de que a representatividade da diversidade entre os seus membros é diminuta. No trabalho de investigação já referido anteriormente, os inquiridos foram questionados se consideravam que os deputados eleitos para o parlamento português representavam adequadamente a diversidade cultural, étnica e religiosa existente em Portugal, ao que a maioria dos entrevistados respondeu que não (Tabela 2).

Tabela 2 - Representatividade da diversidade na Assembleia da República

\begin{tabular}{lccc}
\hline & Brasileiros & Cabo-verdianos & Portugueses \\
\hline Sim & $24,1 \%$ & $18,6 \%$ & $20,0 \%$ \\
\hline Não & $54,3 \%$ & $52,8 \%$ & $68,5 \%$ \\
\hline Não está seguro/Não sabe & $20,1 \%$ & $0,5 \%$ & $10,0 \%$ \\
\hline Não responde & $1,5 \%$ & $28,1 \%$ & $1,5 \%$ \\
\hline
\end{tabular}

Efetivamente, a assunção da representação expressa dos interesses de minorias no parlamento português tem sido circunstancial e limitada no tempo, podendo indicar-se apenas dois casos concretos nos últimos anos: um associado às questóes da imigraçáo e dos negros em Portugal e outro a questóes de orientação sexual.

Embora a maioria dos inquiridos considerasse que a representação da diversidade no parlamento não estava suficientemente assegurada, quando questionados sobre os critérios que utilizavam para a escolha dos representantes, a larga maioria revelou que a filiaçáo étnica ou religiosa nấo era o fator determinante, mostrando antes a sua preferência pela competência técnica (Tabela 3). 
Tabela 3 - Critério para a escolha dos deputados

\begin{tabular}{lccc}
\hline & Brasileiros & Cabo-verdianos & Portugueses \\
\hline Competência técnica dos candidatos & $74,0 \%$ & $68,0 \%$ & $61,5 \%$ \\
\hline Filiação étnica ou religiosa dos candidatos & $3,0 \%$ & $3,0 \%$ & $0,5 \%$ \\
\hline Filiação política/ideológica dos candidatos & $21,0 \%$ & $14,0 \%$ & $25,5 \%$ \\
\hline Não está seguro/Não sabe & $1,0 \%$ & $11,0 \%$ & $10,0 \%$ \\
\hline Não responde & $1,0 \%$ & $4,0 \%$ & $2,5 \%$ \\
\hline
\end{tabular}

Fonte: Costa (2012, p. 272).

Em simultâneo, a maioria deles entendia que a participação dos imigrantes e dos membros dos grupos étnicos e religiosos deveria estar orientada, preferencialmente, para a promoção da igualdade de direitos e deveres e não tanto para a defesa de interesses ou direitos específicos dos imigrantes e das minorias (Tabela 4).

Tabela 4 - Objetivo da participação dos imigrantes e das minorias étnicas e religiosas

\begin{tabular}{lccc}
\hline & Brasileiros & Cabo-verdianos & Portugueses \\
\hline Promover a igualdade de direitos e deveres & $68,5 \%$ & $74,9 \%$ & $58,7 \%$ \\
\hline $\begin{array}{l}\text { Defender interesses culturais e sociais } \\
\text { específicos }\end{array}$ & $12,0 \%$ & $8,0 \%$ & $12,7 \%$ \\
\hline $\begin{array}{l}\text { Garantir existência de quotas e medidas de ação } \\
\text { positiva }\end{array}$ & $13,5 \%$ & $12,1 \%$ & $13,3 \%$ \\
\hline Não está seguro/Não sabe & $3,0 \%$ & $3,5 \%$ & $10,0 \%$ \\
\hline Não responde & $3,0 \%$ & $1,5 \%$ & $5,3 \%$ \\
\hline
\end{tabular}

Fonte: Costa (2012, p. 270).

Deste modo, os dados do trabalho empírico realizado sugerem que mais do que uma preferência étnica, os cidadãos apreciam as soluções que contribuem para a promoção da igualdade, o que significa que existe espaço para a aceitação da construção de soluçóes inclusivas em que a diversidade sirva para estabelecer a igualdade e não tanto seja utilizada para a defesa de soluçóes étnicas específicas e para a proteção e a consolidação dos grupos minoritários. Ou seja, é possível a construção de uma igualdade mais complexa e inclusiva, para 
a qual todos possam contribuir, com preferência sobre a adoção de exceçóes que possam marginalizar e separar os grupos e os indivíduos e sem que atuem sobre as causas da desigualdade e da discriminação.

No entanto, essa construção mais inclusiva da cidadania implica o envolvimento de todos, visto que a ausência de representação política da diversidade e a menor presença associativa e das minorias no espaço público coloca o problema da qualidade e da adequaçáo do debate político para integrar a diversidade existente nas soluçóes aprovadas.

Essa preocupação não encontra tradução nos dois planos para a integração dos imigrantes, nos quais a interculturalidade é objeto de uma apropriação discursiva pelo poder político, sem que seja estabelecida uma estratégia política clara para a promoção da interação dos cidadáos e dos grupos no espaço público, nem incentivada a sua participação no processo de tomada de decisóes.

\section{Referências}

ALEXANDER, Michael. Cities and Labour Immigration: Comparing Policy Responses in Amesterdam, Paris, Rome and Tel Aviv. Hampshire: Ashgate e-book, 2007.

COSTA, Paulo Manuel. Comunidade Política, Imigraçáo e Coesão Social: O caso português. Lisboa: Fundação Calouste Gulbenkian; Fundação para a Ciência e a Tecnologia, 2012.

DIÁRIO DA REPÚBLICA. Resoluçấo do Conselho de Ministros no 63-A/2007. Aprova o Plano para a Integração dos Imigrantes (PII). Diário da República, n. 85, p. 2964(1)-2964(23), 3 maio 2007. Disponível em: <http://dre.pt/pdfgratis/2007/05/08501.pdf>. Acesso em: 24 março. 2014.

Resolução do Conselho de Ministros no 74/2010. Aprova o II Plano para a Integraçáo dos Imigrantes (2010-2013). Diário da República, n. 182, p. 4097-4116, 17 set. 2010. Disponível em: <http://dre.pt/pdf1sdip/2010/09/18200/0409704116.pdf>. Acesso em: 24 março. 2014.

GARCÊS, FERNANDO. De la interculturalidad como armónica relación de diversos, a una interculturalidad politizada. In: MORA, David (Ed.). Interculturalidad Crítica y Descolonización: Fundamentos para el debate. La Paz: III-CAB, 2009. p. 21-49.

WALSH, Catherine. Interculturalidad y colonialidad del poder. Un pensamiento y posicionamento otro desde la diferencia colonial. In: LINERA, Álvaro García; MIGNOLO, Walter.

Interculturalidad, descolonización del estado y del conocimiento. Buenos Aires: Del Signo, 2006. p. 21-70. 
WOOD, Phil; LANDRY, Charles. The Intercultural City: Planning for Diversity Advantage. London: Earthscan, 2008.

Recebido: 04.08.2014

Aceito 01.02.2015

\section{Political interculturalism and the integration of immigrants: the Portuguese case}

\section{Abstract}

The immigrant integration policy aims to promote social cohesion and to forge a sense of identification with the national community, by establishing bonds of solidarity and the sharing of values and practices among all residents in the territory. In Portugal, in recent years, interculturalism has been presented as one of the structuring principles of such a policy. In this article, we intend to show how this policy is reflected in the two first Plans for the Integration of Immigrants, selecting and assessing the measures more directly related to promoting interculturality. We found that the vast majority of measures announced as being intercultural in both documents aims to show the existing cultural diversity and enable the public administration to deal with diversity. While these measures are important to promote and facilitate the integration of immigrants, they are nevertheless not enough to show the intercultural approach of the Portuguese integration policy.

Keywords: Immigration. Integration. Interculturalism. Diversity. Portugal. 